\title{
MAFB modulates the maturation of lymphatic vascular networks in mice
}

\author{
Maria Rondon-Galeano ${ }^{1}$, Renae Skoczylas ${ }^{1,2}$, Neil I. Bower ${ }^{1}$, Cas Simons ${ }^{1,3}$, Emma Gordon ${ }^{1}$, \\ Mathias Francois ${ }^{1,4}$, Katarzyna Koltowska ${ }^{1,2,{ }^{*}}$ and Benjamin M. Hogan ${ }^{1,6,7, *, \# .}$
}

${ }^{1}$ Division of Genomics of Development and Disease, Institute for Molecular Bioscience, The University of Queensland, St Lucia, Brisbane, Queensland 4072, Australia.

${ }^{2}$ Department of Immunology, Genetics and Pathology, Uppsala University, Uppsala, Sweden.

${ }^{3}$ Murdoch Children’s Research Institute, Parkville, VIC 3052, Australia

${ }^{4}$ Centenary Institute, Royal Prince Alfred Hospital, Missenden Rd, Sydney NSW 2050, Australia

${ }^{6}$ Organogenesis and Cancer Program, Peter MacCallum Cancer Centre, Melbourne, VIC 3000, Australia

${ }^{7}$ Department of Anatomy and Neuroscience and Sir Peter MacCallum Department of Oncology, University of Melbourne, Melbourne, VIC 3000, Australia

Author for Correspondence:

\# Professor Ben Hogan

Organogenesis and Cancer Program, Peter MacCallum Cancer Centre, Melbourne, VIC 3000, Australia

E-mail: ben.hogan@petermac.org

*Equal contributors

This is the author manuscript accepted for publication and has undergone full peer review but has not been through the copyediting, typesetting, pagination and proofreading process, which may lead to differences between this version and the Version of Record. Please cite this article as doi: $10.1002 /$ dvdy.209

This article is protected by copyright. All rights reserved. 
Word count: 5263 (Including Figure Legends 6508)

Keywords: MAFB, lymphangiogenesis, lymphatic, vascular, development.

This article is protected by copyright. All rights reserved. 


\begin{abstract}
Background: Lymphatic vessels play key roles in tissue fluid homeostasis, immune cell trafficking and in diverse disease settings. Lymphangiogenesis requires lymphatic endothelial cell (LEC) differentiation, proliferation, migration and co-ordinated network formation, yet the transcriptional regulators underpinning these processes remain to be fully understood. The transcription factor MAFB was recently identified as essential for lymphangiogenesis in zebrafish and in cultured human LECs. MAFB is activated in response to VEGFC-VEGFR3 signalling and acts as a downstream effector. However, it remains unclear if the role of MAFB in lymphatic development is conserved in the mammalian embryo.

Results: We generated a Mafb loss-of-function mouse using CRISPR/Cas9 gene editing. Mafb mutant mice presented with perinatal lethality associated with cyanosis. Mafb mutant lymphatics were normal during initial LEC differentiation and sprouting. However, we identify a role for MAFB in modifying lymphatic network morphogenesis in the developing dermis, as well as developing and postnatal diaphragm. Furthermore, mutant vessels displayed excessive smooth muscle cell coverage, suggestive of a defect in the maturation of lymphatic networks. Conclusions: This work confirms a conserved role for MAFB in murine lymphatics that is subtle and modulatory and may suggest redundancy in MAF family transcription factors during lymphangiogenesis.
\end{abstract}




\section{INTRODUCTION}

The lymphatic vasculature plays pivotal roles in homeostasis, immunity and a range of pathological settings that include cardiovascular diseases and cancer metastasis ${ }^{1}$. Our understanding of the cellular and molecular processes controlling lymphatic vessel development has progressed significantly in the last decade 2,3. Developmental lymphangiogenesis in mice involves the specification and sprouting of lymphatic endothelial cells (LECs) from the cardinal vein (CV). This is followed by formation of transient lymphatic structures and their subsequent sprouting, migration and remodelling to produce lymphatic vessel networks in developing organs and tissues ${ }^{2,4}$. The early specification of LECs is governed by the function of key developmental transcription factors, that are modulated by signalling pathway inputs ${ }^{5-13}$. Prospero homeobox 1 (PROX1) labels the specification of LECs as they transdifferentiate from pre-existing venous endothelial cells (VECs) along the CV from E9 9,14,15. Prox1 knockout mice lack lymphatic vessels from the earliest stages of LEC development and Prox1 is considered the master regulator of LEC fate ${ }^{5}$. The sprouting of LECs from the CV is promoted by Vascular Endothelial Growth Factor C (VEGFC), acting through VEGFR3 ${ }^{16-18}$. Knockout mice in this pathway display Prox1-expression but fail to form sprouting LECs ${ }^{16,19}$. Mutations in the VEGFC/CCBE1/VEGFR3 pathway in humans cause lymphatic dysplasia and lymphoedema ${ }^{20}$. Overexpression of VEGFC or VEGFD is also sufficient to induce lymphangiogenesis in normal tissues and in pathological settings ${ }^{16,21}$, altogether demonstrating the central importance of this signalling pathway in lymphangiogenesis. Finally, an increasing number of signalling, guidance and maturation pathways have also been shown to regulate lymphatic vascular network growth and elaboration 22 .

MAFB is a member of the Maf protein family, which are classified as basic region leucine zipper (bZIP)-type transcription factors ${ }^{23}$. Members of the Maf family share structural similarities with other bZIP-type transcription factors, such as the AP-1 family, but the basic region of the Maf family is unique among the bZIP factors and it contributes to the distinct DNA-binding mode of this class of proteins ${ }^{24}$. The Kreisler mutant was isolated by X-ray 
mutagenesis and was the first Mafb mutant mouse reported ${ }^{25}$. The Kreisler mutation does not disrupt the Mafb coding sequence but reduces rhombdomere 5 and 6 expression of Mafb and causes an ear defect that led to hyperactive behaviour ${ }^{25}$. Another mutant allele identified by ENU mutagenesis ( $k r E N U$ ), reduced Mafb DNA binding activity, due to an Asn-to-Ser substitution at residue 248 within the Mafb DNA binding domain ${ }^{26}$. $k r E N U$ mutant mice had a less severe hindbrain phenotype than Kreisler due to a hypomorphic mutation ${ }^{26}$. Inactivating the Mafb gene by homologous recombination produced a third and null-model that showed that $M a f b$ is required for the development of critical rhythmogenic neurons in the preBötzinger complex ${ }^{27}$. Furthermore, a Mafb/green fluorescent protein (GFP) knock-in null mutant mouse displayed severe renal dysgenesis, characterised by abnormal glomerular differentiation and nephric tubular apoptosis associated with the diminished expression of several kidney diseaserelated genes ${ }^{28}$. Altogether, since these mutant mice were first characterised, Mafb has been demonstrated to play important roles in segmentation of the caudal hindbrain and inner ear development, in haematopoiesis and in podocyte differentiation during mammalian development ${ }^{23,25,26,29}$.

In recent years, the use of the zebrafish model has been highly successful in identifying new, conserved and critical regulators of developmental lymphangiogenesis ${ }^{30}$. A large scale forward genetic screen identified that mafba (there are two homologues in zebrafish) was required for normal lymphatic development and acts during the migration of lymphatic precursors after their initial sprouting from the $\mathrm{CV}^{31}$. Zebrafish mafba expression was enriched in sprouts emerging from veins and mafba functioned cell-autonomously during lymphatic vessel development ${ }^{31}$. Moreover, in zebrafish mafba transcript levels were up-regulated in response to VEGFC, suggesting that it acts as an effector of VEGFC in lymphangiogenesis ${ }^{31}$. Dieterich et al (2015) identified MAFB in vitro as a LEC transcription factor activated by VEGFC. They induced VEGFR3 signalling in primary LECs and subjected the cells to cap analysis of gene expression (CAGE) RNA sequencing at different stages following induction. MAFB activity was particularly strong following stimulation and highly selective to activation in LECs, with MAFB, Klf4 and Sox18 the only transcription factors to display selective upregulation in VEGFC156S-stimulated LECs compared with other cell types ${ }^{32}$. MAFB was expressed in 
developing LECs but not in the blood vasculature, however a simple, initial analysis of the dermal lymphatics in the absence of Mafb revealed only a mild defect in embryonic lymphangiogenesis ${ }^{32}$. More recently, gene expression profiling on mouse retinal endothelial cells (ECs) utilising Ribo-tag technology further suggested that MAFB promotes blood vascular angiogenic cell behaviour. MAFB was enriched in the ECs at the sprouting front of the developing retinal vasculature, MAFB acted cell-autonomously in ECs in vitro and in conditional Mafb knock out mice was found to be an important regulator of blood vascular sprouting ${ }^{33}$. MAFB both upregulated and suppressed target genes to control EC sprouting behaviour in the retina ${ }^{33}$. Thus overall, several recent studies have indicated roles for MAFB in vascular development and lymphangiogenesis in mammals. However, the effect of MAFB deficiency in the context of mammalian lymphatic development in different tissues and organs remains to be explored in detail.

Here, we characterise a novel Mafb mouse model that was generated using CRISPR/Cas9 genome editing ${ }^{34}$. We confirm that MAFB has a role in the early development of lymphatic vessels but this role is mild and only transiently impacts developing networks. Neonatal mutant Mafb mice present with respiratory failure as has been previously described. However, they also display defects in the maturation of lymphatic vessel networks within the diaphragm, while blood vessels appear to be largely unaffected in Mafb mutants. Overall, this study points to a conserved but subtle role for MAFB in embryonic lymphangiogenesis and a role in the maturation of lymphatic networks in the murine diaphragm.

\section{RESULTS}

\section{A Mafb genome-edited mutant phenocopies previous knockout models}

To investigate the role of MAFB in lymphatic development in a mammalian system, we generated a genome-edited Mafb mutant mouse using CRISPR/Cas9 technology as previously

described ${ }^{35}$. The MAF family of transcription factors share a common and well-conserved 
basic region and leucine zipper (bZIP) domain in the carboxy-terminus, which mediates DNA binding and dimer formation ${ }^{36,37}$. We targeted the single-exon coding sequence that encodes for the bZIP DNA binding domain in Mafb (Figure 1A). Mutations generating frameshifts downstream of the CRISPR targeted site are expected to lead to a loss of function allele removing all functional domains of the MAFB protein. Genotyping by PCR from embryonic skin and further sequencing confirmed that Mafb mutant mice generated presented a 56bp deletion in Mafb, leading to removal of codons encoding highly conserved residues, as well as a frame shift leading to a premature stop codon (Figure 1C and 1B). Furthermore, we detected the mutant $M a f b^{456}$ variant by RT-PCR from embryonic tissue and subsequent DNA sequencing, confirming somatic expression of only the mutant variant in homozygous animals (Figure 1C and 1B). Segregation of the $M a f b^{\Delta 56}$ allele was confirmed by PCR on embryos at expected Mendelian frequencies (Figure 1E). Heterozygous $\left(\mathrm{Mafb}^{+/ 456}\right)$ mice developed to adulthood and appeared indistinguishable from wild-type $\left(\mathrm{Mafb}^{+/+}\right)$mice.

We analysed Mafb (Mafb ${ }^{\Delta 56 / 456}$ ) mutant embryos and littermates throughout development and found that Mafb mutant embryos exhibited no gross morphological differences when compared to littermates (Figure 1D). Mafb $b^{456 / 456}$ embryos were analysed at E10.5 (n=19), E11.5 (n=11), E14.5 (n=46), E16.5 (n=59) and E18.5 (n=19), we observed that mutant embryos do not die in utero (Figure 1E). Next, mutants were analysed immediately after birth. Control $\left(\mathrm{Mafb}^{+/+}\right.$and $M a b^{+/ \Delta 56}$ ) pups were easily distinguishable from mutant littermates because they displayed a normal pink colour, consistent with tissue oxygenation 5 minutes after being born. Mafb $\mathrm{fb}^{456 / \Delta 56}$ mutant pups died within 1 hr of birth. Mafb ${ }^{456 / 456}$ pups developed cyanosis, with progressive bluish discoloration of their skin. Furthermore, observation of the lining of the snout, whisker follicles and nail beds showed a darker coloration, indicative of central and peripheral cyanosis (Figure 1F). As cyanosis can be caused by cardiac defects, we examined the basic structure of the heart. Histological analysis revealed a normal heart structure in Mafb ${ }^{456 / \Delta 56}$ pups (Figure 1G) and they exhibited gasping and costal retractions, indicative of normal neuromuscular function and respiratory drive (Video 1). Overall, Mafb $b^{456 / \Delta 56}$ mutant neonates manifested traits consistent with respiratory failure immediately after birth. This is entirely consistent with 
previous publications of Mafb knockout mouse phenotypes, which also present gasping behaviour, cyanosis and death soon after birth ${ }^{27}$, and thus these data support the molecular lesion being a loss-of-function allele.

\section{MAFB deficient lungs display reduced alveolar area and septal thickening}

To further investigate the cause of lethality in $M a f b^{456 / 456}$ neonates, lungs were collected within 30 minutes of birth for further analysis. Haematoxylin and Eosin (H\&E) staining on coronal lung tissue sections showed reduced alveolar area in Mafb mutant lungs compared to littermates (Figure 2A). Mafb mutant lungs showed an increase in alveolar interstitial thickness when compared to control littermates (Figure 2A and B). Moreover, upon trichome (TRI) staining, we observed normal distribution of collagen fibres (Type I and III Collagen) in the neonate mutant lungs and control litter mates, indicating that lung fibrosis is not the cause of the respiratory failure present in Mafb mutant mice (Figure 2A). We next measured and compared the total DNA content between $M a f b^{\Delta 56 / \Delta 56}$ mutant lungs and controls, and observed a subtle increase only in the mutant lungs, indicating that the differences in lung structure are not an artefact of stunted growth or any major fibrotic infiltrates (Figure 2C). To further understand the lung phenotype caused by lack of MAFB, we designed an RNA probe to detect Mafb gene expression in the lungs. We performed in situ hybridisation in lung sections at P0. We found Mafb expression in the bronchioles as well as in vasculature (Figure 2D). This observation of broad expression in multiple cell types in lung, that include endothelial cells, is consistent with recently published single cell sequencing atlas data ${ }^{38,39}$.

Type I pneumocytes cover approximately 95\% of the alveolar surface ${ }^{40,41}$, Type II pneumocytes (composed of surfactant in the centre of the alveolar barrier) and the endothelial cells of the alveolar capillaries are located directly beneath the alveolar lining cells ${ }^{40,41}$. Immunostaining in transverse lung tissue sections identified Type I pneumocytes (PODOPLANIN+; CAVEOLIN1+) in both mutant and control lungs (Figure 2E). Type II pneumocytes were also detected and unchanged in mutants based on Periodic acid-Schiff 
(PAS) staining ${ }^{42}$ (Figure 2A). Likewise, smooth muscle cells (SMA), pericytes (NG2) and lymphatic vessels (LYVE-1+; PROX1+) were unchanged in Mafb mutant neonates (Figure 2E). These results together indicate that the absence of Mafb does not dramatically affect the cellular composition of the lung but a thickening of interstitia of the alveoli walls and reduced alveoli size likely leads to a partial inflation of the lung, which is likely to cause the cyanotic effect observed in Mafb ${ }^{456 / 456}$ pups. This is again consistent with previous reports ${ }^{27}$ and the molecular lesion being a loss-of-function allele.

\section{Mafb mutant dermal lymphatics present a mild and transient delay in development}

To analyse the role of MAFB in embryonic lymphatic development, we dissected back-skins from E14.5 and E16.5 Mafb mutant embryos and control littermates. We stained them for blood endothelial cell (BEC) and LEC markers (ENDOMUCIN, LYVE-1 and PROX1; Figure 3A and 3B). Quantification from embryonic skins at E14.5 showed that there was no significant difference in the number of LECs (PROX1+;NEUROPILIN-2+), the number of vessel branch points, the width of vessels at the migrating front or the number of vessel loops in the lymphatic networks in mutants compared with controls (Figure 3C). Despite appearing to be largely normal, the dermal lymphatic vasculature of $M a b^{456 / \Delta 56}$ embryos did show a mild but statistically significant delay in vessel migration, as measured by the mean distance from the midline to the closest migrating vessel. This suggests that MAFB does not play a major, nonredundant, role in developmental lymphangiogenesis in the skin. To determine if the early mild defects in lymphangiogenesis led to more profound later phenotypes, we next examined E16.5 embryonic skins but found that they showed no difference in the number of vessel branch points, number of LECs (PROX1+;NEUROPILIN-2+), number of loops or distance from the midline to the closest migrating vessel in the lymphatic networks in mutants compared with controls (Figure 3D). Interestingly, lymphatic vessel width at the migrating front was mildly broader in Mafb $\mathrm{b}^{456 / 456}$ embryos when compared to controls at this time point but overall the developing lymphatic vasculature appeared to have recovered from its earlier delay in midline 
migration. MAFB has recently been implicated in blood vascular angiogenesis in the retina ${ }^{33}$. To understand if the mild lymphatic phenotypes observed might occur due to underlying blood vessel defects, we measured blood vessel coverage, width, branch points and number of loops at E14.5 (Figure 3C) and E16.5 (Figure 3D). We observed no significant changes in the skin blood vasculature between $M a f b^{456 / 456}$ and control littermates, perhaps suggesting that the reported retinal vascular defect uncovers an organ specific role for MAFB in blood vessels, rather than a generalisable function. Overall, these observations are consistent with previous analyses at E14.5 ${ }^{32}$, however we find that lymphangiogenesis largely recovers by late developmental stages (E16.5) and mild earlier defects (E14.5) appear to be transient.

\section{MAFB is necessary to pattern the lymphatics of the diaphragm}

To investigate whether MAFB might play roles in lymphangiogenesis in other tissues, we analysed the lymphatic vessels on the pleural side of the diaphragm. Development of the lymphatics in the diaphragm has been reported to initiate from as early as E16.5, with network maturation occurring through postnatal stages ${ }^{43}$. We dissected diaphragms from mutant and control embryos at E16.5 and P0 (Figure 4A and B). We immunostained against BECs and LECs (ENDOMUCIN, NEUROPILIN-2 and PROX1) and selected a consistent area (Figure 4A and 4B, dotted square) of the left diaphragm for quantification. Mutant diaphragms at E16.5 (Figure 4A) showed an increase in the area covered by lymphatic vessels (PROX1+; NEUROPILIN-2+), as well as in the total number of LECs in migrating vessels compared to control diaphragms. Furthermore, the lymphatic vessels of the mutant diaphragms were significantly broader than controls, and the number of LECs was higher at vessel branch points (Figure 4C). Similar to defects seen in early diaphragm development, quantification of mutant diaphragms at P0 in the postnatal mouse (Figure 4B) revealed an increase in the total area covered by lymphatic vessels (PROX1+; NEUROPILIN-2+). At P0, the number of LECs at the tip of migrating vessels was not increased in mutants and the number of LECs at vessel branch points did not differ significantly. However, we observed that lymphatic vessels of the 
mutant diaphragms were markedly broader than those of controls (Figure 4E). Furthermore, when we quantified the vessel width and number of branch points of the blood vasculature between $M a f b^{456 / 456}$ and control littermates in the diaphragm at E16.5 (Figure 4D) and P0 (Figure 4F), there were no significant differences. Overall, the most consistent observation during the development of the diaphragm lymphatics in Mafb mutant mice was that the width of the vessels was consistently broader at E16.5 and P0.

We noted at both time-points that lymphatic vessels in mutants appeared to display distinctly rounded vessel ends (sprouts) with a bulbous morphology (Figures $4 B$ and 5A). We measured the width of lymphatic vessels in the diaphragm at the migrating vessel front in E16.5 embryos (Figure 5A and 5B) and found that vessels were significantly wider in the Mafb ${ }^{456 / 456}$ embryos. To assess cellular morphology and spreading, given consistent increases in vessel width, we quantified the distance between nuclei at these lymphatic vessel tips in migrating vessels at E16.5 and found that the distance between nuclei was higher in the Mafb mutant embryos than in control littermates (Figure 5A and 5C). These observations suggest that cells are more spread, leading to broader vessels in Mafb mutant networks. This may be consistent with a defect in the maturation of lymphatic networks in the absence of MAFB. To further investigate if similar defects are seen in other developing lymphatic networks, we examined the mesenteric lymphatic vessels. Due to lethality at P0 (Figure 1E), we analysed the developing mesenteric lymphatics at E18.5 (Figure 5D). We saw no marked differences between Mafb mutants and littermates in the length of collecting vessels, the number of Prox1-high expressing pre-valve regions or the number of forming valves normalised along the vessel length (Figure 5E). This may suggest that Mafb function is restricted to some vessel beds but not others, or that a later role in mesenteric vessels is masked by perinatal lethality in this CRISPR knockout model.

\section{MAFB is required for normal mural cell coverage of developing lymphatic networks}

To further assess the maturation of MAFB deficient lymphatic vessels, we examined the mural cell coverage of the lymphatics. Previous studies have shown that altered mural cell coverage 
can indicate defects in vessel differentiation or maturation ${ }^{44-46}$. We stained embryonic back skins at E16.5 (Figure 6A) and diaphragms at P0 (Figure 6B) for alpha smooth muscle actin (SMA). We analysed smooth muscle coverage over equivalent regions of the vasculature using the software Imaris (Bitplane Scientific Software) to measure surface coverage with actinpositive mural cells (Figure 6C). At E16.5, we found that the major lymphatics of the skin showed large patches with increased mural cell (SMA) coverage with up to 55\% of some vessels covered by mural cells compared with $5 \%$ in littermate controls (Figure 6D). Moreover, we examined diaphragms at P0 and observed a similar phenotype with up to 39\% smooth cell coverage (SMA) in mutant diaphragms compared to $7 \%$ in control diaphragms (Figure 6E). Overall, this observation in 2 different lymphatic vessel networks suggests that MAFB is needed to regulate normal mural cell coverage of lymphatic vessels in some vessel beds during development. While MAFB is notably expressed in both ECs and mural cells 38,39, coupled with the vascular morphogenesis defects described above, this observation may be consistent with a defect in vascular maturation in the absence of Mafb.

\section{DISCUSSION}

In the present study, we investigated the role of the transcription factor MafB in the development of the lymphatic system in mice. Our previous studies in zebrafish identified that mafba is essential for lymphatic vessel development, controlling the migration of lymphatic precursors ${ }^{31}$ and work in cultured human LECs has suggested a conserved function for this transcription factor in lymphangiogenesis ${ }^{32}$. Thus, we generated a novel MafB mouse model targeting the single-exon coding sequence in the Mafb gene using CRISPR mutagenesis. To verify the generation of a deletion, we performed gDNA analysis and also RT-PCR analysis of skin mRNA and confirmed a 56bp deletion which leads to an early stop codon. Additionally, previous studies have shown that Mafb mutant neonates do not survive past birth ${ }^{28}$, presenting difficulty in breathing and cyanosis ${ }^{27}$. During the final revision stages of this study, the conditional knockout of MafB in lymphatic vasculature was reported by Dieterich et al (2020), 
demonstrating similar findings to our observations in this global CRISPR generated knockout model ${ }^{47}$. Our MafB mouse model thus shows phenotypes consistent with other reports, further establishing it as a Mafb loss-of-function model predicted by the genetic lesion.

Mafb mutant mice do not survive after birth, presenting with respiratory failure and consequent cyanosis. These phenotypes could be seen as similar to lymphatic deficient Ccbe1 knockout mice, which fail to inflate their lungs after birth and also display cardiac phenotypes ${ }^{48,49}$. However, unlike Ccbe1-deficient mice, Mafb mutant lungs contain lymphatic vessels. MAFB is also broadly expressed in lung ECs, smooth muscle cells, Fibroblasts and immune cells ${ }^{38,39}$ and thus further studies are needed to determine the precise cause of this phenotype. Previous studies have reported a mild defect in lymphangiogenesis at E14.5 in Mafb knockout mice ${ }^{32}$ and we confirmed this observation in our own model. To study the consequences of lack of MAFB in late development and extend on these previous studies, we analysed back skins at E16.5. Surprisingly, the lymphatic network appeared to have recovered by later stages of development indicating that in the developing skin lymphatics the influence of MAFB is subtle or modulatory. In addition, MAFB has been shown to be essential for retinal angiogenesis in a conditional knockout model ${ }^{33}$, when we characterized the blood vascular network in the dermis and in the diaphragm, we observed no phenotype in the blood vasculature. This suggests that beyond the retina, a role for MAFB in blood vessel angiogenesis is not pervasive or consistent between organs and tissues.

Mafb mutant lymphatic vessels in the diaphragm were broader and covered a larger area of the diaphragm with only a slight increase in the number of LECs in the migrating vessels. Rather than a strong increase in cell number, the distance between LEC nuclei is increased in the Mafb mutant diaphragms, indicating that cells are more spread, displaying morphogenesis defects in mutant lymphatics. Notably, in the diaphragm we observed a similar scenario to that in back skins, the phenotype is stronger earlier in lymphatic development and appears to resolve to a milder defect as development progresses. These observations demonstrate that Mafb does have an essential function in the formation of lymphatic vascular networks in mammals. As a transcription factor, MAFB may regulate vessel morphogenesis via specific downstream 
targets. Indeed, known Mafb targets in ECs include regulators of G-protein signalling, Rac1 and Erk signalling ${ }^{33}$, the modulation of which could lead to phenotypes such as those that we describe here.

The relatively mild phenotype that normalises somewhat over time, is in contrast to the profound loss of lymphatics seen upon loss of Mafba in zebrafish ${ }^{31}$. The large Maf family of transcription factors contains 4 proteins (including MAFA, MAFB, c-MAF, and NRL) that have highly conserved amino acid sequences in the DNA binding domain. MAFA and MAFB proteins exhibit the same sequence specificity and both $\mathrm{Mafb}$ and $\mathrm{Nrl}$ are highly homologous to one another not only in their bZIP domain but also in the amino-terminal acidic domain ${ }^{23}$. Thus, it is plausible that in the mammalian setting the absence of MAFB may be compensated for by the complementary activity of similar transcription factors of the large Maf family. This has been observed before in the small Maf family, a Mafk null mutant mice appeared to be normal and healthy ${ }^{50}$ and the chicken small Maf proteins are able to functionally substitute for one another ${ }^{51}$, with it proposed that MAFF or MAFG can compensate for loss of MAFK function. Further studies generating knockout models of multiple Maf transcription factors are needed in the future to clarify the extent of redundant control of lymphangiogenesis by these factors.

One of the major outstanding questions is how does MafB mechanistically influence lymphatic vascular development? Is it a regulator of tissue differentiation, cell migration or other discrete cellular processes? To facilitate the transport of lymph, collecting lymphatics recruit and are surrounded by SMCs, thus recruitment of SMCs is part of the normal maturation of lymphatic vessels ${ }^{22,52}$. Failure in SMCs recruitment or aberrant recruitment by the lymphatic capillaries contributes to vessel failure, leads to lymphedema and has been demonstrated to be a hallmark of altered vessel differentiation ${ }^{44-46,53}$. Here, we observed an excessive coverage of alpha smooth cell actin in the dermal and diaphragm lymphatics in Mafb mutant mice. This is consistent MafB influencing the maturation of the lymphatic network during tissue vascular development, via EC autonomous or non-autonomous mechanisms. Future studies will need to decode the key Maf-transcription factor target genes that influence and control lymphatic 
maturation, such further mechanistic analyses will potentially lead to new downstream pathways and targets of relevance in lymphatic homeostasis and pathologies.

\section{ACKNOWLEDGEMENTS}

This work was supported by a National Health and Medical Research Council of Australia (NHMRC Australia) Project grant (1107755). K.K. was supported by a Lymphatic Education and Research Network (LE\&RN) Postdoctoral Fellowship. BMH was supported by a National Heart Foundation/NHMRC Career Development Fellowship (1083811). Imaging was performed in the Australian Cancer Research Foundation's Cancer Ultrastructure and Function Facility at the IMB and the Petermac Centre for Advanced Histology and Microscopy (CAHM).

\section{EXPERIMENTAL PROCEDURES}

\section{Animals.}

To generate the $M a f b^{456}$ loss-of-function mouse we used the published protocol ${ }^{35}$ with following modifications: two guides 22bp apart from each other were designed within the Mafb DNA binging domain. The CHOPCHOP online tool was used to design the guides ${ }^{54}$. Oocytes collected from CBB6F1 mice were co-injected with two guide RNAs at 5ng/ $\mu$ l concentration each and with CasRNA at 10ng/ $\mu$ l concentration. From 3 rounds of injection 23 live born pups were obtained and 2 carried the mutated DNA, using genotyping primers and further sequencing a 56bp deletion was confirmed from base 709-764 of the annotated coding sequence (Gene ID: 16658). The MafB mutant mouse was maintained on a mixed background - backcrossing to C57BL6 4 times at the time of collection for time matings. Guides sequences (PAM in bold): $M a f b$ - guide1 - 5' - CGTCCTTGGTGAAGCCCCGCAGG - 3'; Mafb guide2 - 5' - GCGGCGGACCCTGAAGAACCGGG - 3'. Cloning primers for pX330 (overhang specific sequence in bold): Mafb - guide1 Forward - 5' - 
CACCGCGTCCTTGGTGAAGCCCCGC - 3’; Mafb - guide1 Reverse - 5' AAACGCGGGGCTTCACCAAGGACGC - 3'; Mafb - guide2 Forward - 5' CACCGGCGGCGGACCCTGAAGAACC - 3’; Mafb - guide2 Reverse - 5' AAACGGTTCTTCAGGGTCCGCCGCC - 3'. Transcription primers for T7 promoter: Mafb - guide1 T7 Forward - 5' taatacgactcactatagGCGTCCTTGGTGAAGCCCCGC - 3'; Mafb guide2 T7 Forward - 5' ttaatacgactcactatagGGCGGCGGACCCTGAAGAACC - 3'; common - T7 Reverse - 5' aaaagcaccgactcggtgcc - 3'. Genotyping primers: Mafb - geno Forward - 5' - CGCAACAGCTACCCACTAGCC - 3' and Mafb - geno Reverse - 5' GGAGTTGGCGAGTTTCTCGCAC - 3'. All animal experiments were approved by The University of Queensland’s Molecular Biosciences Animal Ethics Committee (AEC).

\section{Timed matings and handling of late gestation embryos.}

Overnight timed matings were set up using $M a f b^{+/ 456}$ animals. Embryos from these crosses were collected at E10.5, E11.5, E14.5, E16.5, E18.5, E19 and naturally born embryos were monitored for 30', sacrificed and tissues were harvested. Lungs and hearts were collected for histology, or lung dissection for testing flotation, wet-to-dry measurements and DNA content.

\section{Histological procedures and immunohistochemistry.}

Lungs and hearts were fixed in $4 \%$ paraformaldehyde overnight at $4{ }^{\circ} \mathrm{C}$, dehydrated in serial ethanol washes, and a final xylene incubation prior embedding in paraffin. $7-\mu \mathrm{m}$-thick sections were stained with hematoxylin and eosin (H\&E), periodic acid-Schiff (PAS) and trichrome (TRI) using standard procedures, sections were then embedded in Entellan New, mounting medium (ProSciTech. Cat. \#IM022). Sections were imaged using Olympus BX51 Upright Microscope Stand with Olympus DP70 CCD camera with a 4x, 10x or 20x objective.

Immunofluorescence of lung sections was performed as previously described ${ }^{55}$. Tissues were fixed in $4 \%$ paraformaldehyde overnight at $4{ }^{\circ} \mathrm{C}$, washed several times with phosphate-buffered saline (PBS) and incubated in blocking solution (10\% horse serum, 1\%DMSO, 100mM Maleic 
acid - pH 7.5, 0.1\% Triton X-100 in PBS) for 1 hour, followed by incubation overnight with primary antibody, the next day after extensive washes in PBS, tissues were incubated overnight with secondary antibody. Finally, tissues were mounted on glass slides with VECTASHIELD ${ }^{\circledR}$ Antifade Mounting Medium (Vector Laboratories. Cat. \# H-1000). Tissues and lung sections were imaged on Zeiss Axiovert 200 Upright Microscope Stand with LSM 710 Meta Confocal Scanner and/or Zeiss Axiovert 200 Inverted Microscope Stand with LSM 880 Confocal Scanner with Fast Airyscan Detector with a 10x, 20x or 63x objectives.

The following primary antibodies were used for immunostaining: anti-mouse LYVE1 (AngioBio. Cat. \# 11-034), anti-PROX1 (AngioBio. Cat. \# 11-002), anti-mouse Podoplanin (AngioBio. Cat. \# 11-033), Caveolin-1 (Cell Signaling. Cat. \# 3238S), and Anti-NG2 Chondroitin Sulfate Proteoglycan Antibody (Merck. Cat. \#AB5320), anti-NG2. Anti-alpha smooth muscle Actin antibody (Abcam. Cat. \# 5694), Mouse/Rat Neuropilin-2 Antibody (R\&D Systems. Cat. \# AF567), Endomucin Antibody (V.5C7) (Santa Cruz. Cat. \# sc-53941). Secondary antibodies: Donkey anti-Goat IgG $(\mathrm{H}+\mathrm{L})$ Cross-Adsorbed, Alexa Fluor 488 (Invitrogen. Cat. \# A11055), Goat anti-Rat IgG (H+L) Cross-Adsorbed, Alexa Fluor 647 (Invitrogen. Cat. \# A21247), Donkey anti-Rabbit IgG (H+L) Highly Cross-Adsorbed, Alexa Fluor 594 (Invitrogen. Cat. \#A21207) and 6-Diamidino-2-Phenylindole (DAPI) to stain nuclei.

\section{In-situ hybridization}

The probe for Mafb was made as previously described ${ }^{56}$, nucleotides 897-1873 of the mouse Mafb transcript ENSMUST00000099126.4. Section in situ hybridization (SISH) was performed on 7- $\mu \mathrm{m}$ sections of paraformaldehyde-fixed, paraffin-embedded embryos. Sections were dewaxed, rehydrated, and incubated in $10 \mu \mathrm{g} / \mathrm{ml}$ proteinase $\mathrm{K}$ for $20 \mathrm{~min}$ at room temperature. After washing in PBS, sections were refixed with 4\% paraformaldehyde for 10 min at room temperature, acetylated, and prehybridized with hybridization solution (50\% formamide, $5 \times$ SSC, $5 \times$ Denhardt's, $250 \mu \mathrm{g} / \mathrm{ml}$ yeast RNA, $500 \mu \mathrm{g} / \mathrm{ml}$ herring sperm DNA) for $2 \mathrm{~h}$ at room temperature. Hybridization (hybridization solution $+0.5 \mu \mathrm{g} / \mathrm{ml}$ probe) was performed overnight at $68^{\circ} \mathrm{C}$. Slides were washed in $5 \times$ SSC for $5 \mathrm{~min}, 0.2 \times$ SSC for $1 \mathrm{~h}$ at 68 
${ }^{\circ} \mathrm{C}, 0.2 \times \mathrm{SSC}$ for $5 \mathrm{~min}$ at room temperature and NT buffer $(150 \mathrm{mM} \mathrm{NaCl}, 50 \mathrm{mM}$ Tris- $\mathrm{HCl}$, $\mathrm{pH}$ 7.5) for $5 \mathrm{~min}$ at room temperature before incubating for $2 \mathrm{~h}$ with blocking solution (10\% heat-inactivated sheep serum in NT buffer) in a humidified chamber. Anti-digoxigenin antibody (Roche Applied Science) at 1:2000 dilution in blocking solution was added to the slides and incubated overnight at $4{ }^{\circ} \mathrm{C}$. Unbound antibodies were removed by washing three times in NT buffer. Sections were equilibrated in NTM buffer (100 mM NaCl, $100 \mathrm{mM}$ Tris$\mathrm{HCl}, \mathrm{pH}$ 9.5, $50 \mathrm{mM} \mathrm{MgCl}$ ) and incubated in color solution (3.5 $\mu$ l of 5-bromo-4-chloro-3indolyl phosphate (Roche Applied Science), $3.5 \mu \mathrm{l}$ of nitro blue tetrazolium (Roche Applied Science) per ml of NTM buffer) until staining was satisfactory.

\section{RT-PCR}

Total RNA was extracted from selected tissues and organs using RNeasy mini kit (Qiagen, Chatsworth, USA) following manufacturer's instructions. RNA was amplified using the Agilent low input Quick Amp Labelling kit (Agilent technologies, Santa Clara, USA). cDNA synthesis was performed using a Quantitect reverse transcription kit (Qiagen, Chatsworth, USA) following manufacturer's instructions. Primers: Mafb - cds Forward - 5' CAAAGTTTTCCCCGCGGCAG - 3' and Mafb - cds Reverse - 5' TAGGGGCGCAGAATAGGGAG - 3’.

\section{DNA content measurements.}

Explanted Mafb $b^{456 / 456}$ and control lungs were harvested $\sim 30$ ' min after natural birth. Total DNA content was isolated from the whole lungs of $M a f b^{\Delta 56 / 456}$ and control P0 lungs using a Dneasy Blood \&Tissue Kit (Qiagen. Cat. \#69504). DNA concentration of the samples was determined by a NanoDrop 1000 system (Thermo Fisher Scientific).

\section{Statistical analysis.}

This article is protected by copyright. All rights reserved. 
Image processing and analysis were performed using Fiji software (National Institutes of Health) and Imaris (Bitplane Scientific Software). Results are shown as mean and SEM. Statistical analyses were performed using Student unpaired two-tailed t test using Prism 8 (GraphPad Software). Differences were considered statistically significant at $\mathrm{P}<0.05$.

\section{Online supplemental material.}

Video 1: $M a f b^{456 / 456}$ and control littermate neonates are born alive and exhibit gasping and costal retractions, indicative of normal neuromuscular function and respiratory drive. Video shows a mutant at P0 on the right.

This article is protected by copyright. All rights reserved. 


\section{REFERENCES}

1. Jurisic G, Detmar M. Lymphatic endothelium in health and disease. Cell Tissue Res. Jan 2009;335(1):97-108. https://doi.org10.1007/s00441-008-0644-2.

2. Koltowska K, Betterman KL, Harvey NL, Hogan BM. Getting out and about: the emergence and morphogenesis of the vertebrate lymphatic vasculature. Development. May 2013;140(9):1857-70. https://doi.org10.1242/dev.089565.

3. Petrova TV, Koh GY. Organ-specific lymphatic vasculature: From development to pathophysiology. J Exp Med. Jan 2 2018;215(1):35-49. https://doi.org10.1084/jem.20171868.

4. Detmar M, Hirakawa S. The formation of lymphatic vessels and its importance in the setting of malignancy. J Exp Med. Sep 16 2002;196(6):713-8. https://doi.org10.1084/jem.20021346.

5. Wigle JT, Oliver G. Prox1 Function Is Required for the Developmentof the Murine Lymphatic System. Cell. 1999;98:9.

6. Francois M, Caprini A, Hosking B, et al. Sox18 induces development of the lymphatic vasculature in mice. Nature. Dec 4 2008;456(7222):643-7. https://doi.org10.1038/nature07391.

7. Srinivasan RS, Geng X, Yang Y, et al. The nuclear hormone receptor Coup-TFII is required for the initiation and early maintenance of Prox1 expression in lymphatic endothelial cells. Genes Dev. Apr 1 2010;24(7):696-707. https://doi.org10.1101/gad.1859310.

8. Hagerling R, Pollmann C, Andreas M, et al. A novel multistep mechanism for initial lymphangiogenesis in mouse embryos based on ultramicroscopy. EMBO J. Mar 6 2013;32(5):629-44. https://doi.org10.1038/emboj.2012.340.

9. Yang Y, Garcia-Verdugo JM, Soriano-Navarro M, et al. Lymphatic endothelial progenitors bud from the cardinal vein and intersomitic vessels in mammalian embryos. Blood. Sep 13 2012;120(11):2340-8. https://doi.org10.1182/blood-2012-05428607.

10. Srinivasan RS, Oliver G. Prox1 dosage controls the number of lymphatic endothelial cell progenitors and the formation of the lymphovenous valves. Genes Dev. Oct 15 2011;25(20):2187-97. https://doi.org10.1101/gad.16974811.

11. Deng Y, Atri D, Eichmann A, Simons M. Endothelial ERK signaling controls lymphatic fate specification. J Clin Invest. Mar 2013;123(3):1202-15. https://doi.org10.1172/JCI63034.

12. Duong T, Koltowska K, Pichol-Thievend C, et al. VEGFD regulates blood vascular development by modulating SOX18 activity. Blood. Feb 13 2014;123(7):1102-12. https://doi.org10.1182/blood-2013-04-495432.

13. Koltowska K, Lagendijk AK, Pichol-Thievend C, et al. Vegfc Regulates Bipotential Precursor Division and Prox1 Expression to Promote Lymphatic Identity in Zebrafish. Cell Rep. Dec 1 2015;13(9):1828-41. https://doi.org10.1016/j.celrep.2015.10.055. 
14. Srinivasan RS, Dillard ME, Lagutin OV, et al. Lineage tracing demonstrates the venous origin of the mammalian lymphatic vasculature. Genes Dev. Oct 1 2007;21(19):2422-32. https://doi.org10.1101/gad.1588407.

15. Wigle JT, Harvey N, Detmar M, et al. An essential role for Prox1 in the induction of the lymphatic endothelial cell phenotype. EMBO J. Apr 2 2002;21(7):1505-13. https://doi.org10.1093/emboj/21.7.1505.

16. Karkkainen MJ, Haiko P, Sainio K, et al. Vascular endothelial growth factor $\mathrm{C}$ is required for sprouting of the first lymphatic vessels from embryonic veins. Nat Immunol. Jan 2004;5(1):74-80. https://doi.org10.1038/ni1013.

17. Dumont DJ, Jussila L, Taipale J, et al. Cardiovascular failure in mouse embryos deficient in VEGF receptor-3. Science. Oct 30 1998;282(5390):946-9. https://doi.org10.1126/science.282.5390.946.

18. Karkkainen MJ, Saaristo A, Jussila L, et al. A model for gene therapy of human hereditary lymphedema. Proc Natl Acad Sci U S A. Oct 23 2001;98(22):12677-82. https://doi.org10.1073/pnas.221449198.

19. Bos FL, Caunt M, Peterson-Maduro J, et al. CCBE1 is essential for mammalian lymphatic vascular development and enhances the lymphangiogenic effect of vascular endothelial growth factor-C in vivo. Circ Res. Aug 19 2011;109(5):486-91. https://doi.org10.1161/CIRCRESAHA.111.250738.

20. Mendola A, Schlogel MJ, Ghalamkarpour A, et al. Mutations in the VEGFR3 signaling pathway explain 36\% of familial lymphedema. Mol Syndromol. Sep 2013;4(6):257-66. https://doi.org10.1159/000354097.

21. Stacker SA, Caesar C, Baldwin ME, et al. VEGF-D promotes the metastatic spread of tumor cells via the lymphatics. Nat Med. Feb 2001;7(2):186-91. https://doi.org10.1038/84635.

22. Yang Y, Oliver G. Development of the mammalian lymphatic vasculature. J Clin Invest. Mar 2014;124(3):888-97. https://doi.org10.1172/JCI71609.

23. Kataoka K, Fujiwara KT, Noda M, Nishizawa M. MafB, a New Maf Family Transcription Activator That Can Associate with Maf and Fos but Not with Jun. Molecular and Cell Biology. 1994:10.

24. Katsuoka F, Yamazaki H, Masayuki Y. Small Maf deficiency recapitulates the liver phenotypes of Nrf1- and Nrf2-deficient mice. Genes to Cells. 2016;21:10.

25. Cordes SP, Barsh GS. The mouse segmentation gene kr encodes a novel basic domain-leucine zipper transcription factor. Cell. Dec 16 1994;79(6):1025-34. https://doi.org10.1016/0092-8674(94)90033-7.

26. Sadl V, Jin F, Yu J, et al. The mouse Kreisler (Krml1/MafB) segmentation gene is required for differentiation of glomerular visceral epithelial cells. Dev Biol. Sep 1 2002;249(1):16-29. https://doi.org10.1006/dbio.2002.0751.

27. Blanchi B, Kelly LM, Viemari JC, et al. MafB deficiency causes defective respiratory rhythmogenesis and fatal central apnea at birth. Nat Neurosci. Oct 2003;6(10):1091100. https://doi.org10.1038/nn1129.

28. Moriguchi T, Hamada M, Morito N, et al. MafB is essential for renal development and F4/80 expression in macrophages. Mol Cell Biol. Aug 2006;26(15):5715-27. https://doi.org10.1128/MCB.00001-06. 
29. Eichmann A, Grapin-Botton A, Kelly L, Graf T, Le Douarin NM, Sieweke M. The expression pattern of the mafB/kr gene in birds and mice reveals that the kreisler phenotype does not represent a null mutant. Mech Dev. Jul 1997;65(1-2):111-22.

30. Hogan BM, Schulte-Merker S. How to Plumb a Pisces: Understanding Vascular Development and Disease Using Zebrafish Embryos. Dev Cell. Sep 25 2017;42(6):567-583. https://doi.org10.1016/j.devcel.2017.08.015.

31. Koltowska K, Paterson S, Bower NI, et al. mafba is a downstream transcriptional effector of Vegfc signaling essential for embryonic lymphangiogenesis in zebrafish. Genes Dev. Aug 1 2015;29(15):1618-30. https://doi.org10.1101/gad.263210.115.

32. Dieterich LC, Klein S, Mathelier A, et al. DeepCAGE Transcriptomics Reveal an Important Role of the Transcription Factor MAFB in the Lymphatic Endothelium. Cell Rep. Nov 17 2015;13(7):1493-1504. https://doi.org10.1016/j.celrep.2015.10.002.

33. Jeong HW, Hernandez-Rodriguez B, Kim J, et al. Transcriptional regulation of endothelial cell behavior during sprouting angiogenesis. Nat Commun. Sep 28 2017;8(1):726. https://doi.org10.1038/s41467-017-00738-7.

34. Yang H, Wang H, Jaenisch R. Generating genetically modified mice using CRISPR/Cas-mediated genome engineering. Nat Protoc. Aug 2014;9(8):1956-68. https://doi.org10.1038/nprot.2014.134.

35. Croft B, Ohnesorg T, Hewitt J, et al. Human sex reversal is caused by duplication or deletion of core enhancers upstream of SOX9. Nat Commun. Dec 14 2018;9(1):5319. https://doi.org10.1038/s41467-018-07784-9.

36. Blank V, Andrews NC. The Maf transcription factors: regulators of differentiation. Trends in Biochemical Sciences. 1997;22(11):437-441.

37. Motohashi H, Shavit JA, Igarashi K, Yamamoto M, Engel JD. The world according to Maf. Nucleic Acids Research. 1997;25(15):2953-2959.

38. He L, Vanlandewijck M, Mae MA, et al. Single-cell RNA sequencing of mouse brain and lung vascular and vessel-associated cell types. Sci Data. Aug 21 2018;5:180160. https://doi.org10.1038/sdata.2018.160.

39. Vanlandewijck M, He L, Mae MA, et al. A molecular atlas of cell types and zonation in the brain vasculature. Nature. Feb 22 2018;554(7693):475-480.

https://doi.org10.1038/nature25739.

40. Morgenroth K, Ebsen M. Anatomy. In: Papadakos P, Lachmann B, eds. Mechanical Ventilation. 2008. Chapter 8:688.

41. Wright JL, Chrurg AM. Macro and Micro Structure of the Lung. In: Spiro GS, Silvestri GA, Agusti A, eds. Clinical Respiratory Medicine. 4th ed.: 2012. Chapter 1:1000.

42. Fu C, Lu H, Wu X, et al. Chronic intermittent hypoxia decreases pulmonary clearance of (99m)Tc-labelled particulate matter in mice. Am J Transl Res. 2017;9(6):30603072.

43. Ochsenbein AM, Karaman S, Proulx ST, et al. Regulation of lymphangiogenesis in the diaphragm by macrophages and VEGFR-3 signaling. Angiogenesis. Oct 2016;19(4):513-24. https://doi.org10.1007/s10456-016-9523-8. 
44. Norrmen C, Ivanov KI, Cheng J, et al. FOXC2 controls formation and maturation of lymphatic collecting vessels through cooperation with NFATc1. J Cell Biol. May 4 2009;185(3):439-57. https://doi.org10.1083/jcb.200901104.

45. Lutter S, Xie S, Tatin F, Makinen T. Smooth muscle-endothelial cell communication activates Reelin signaling and regulates lymphatic vessel formation. J Cell Biol. Jun 11 2012;197(6):837-49. https://doi.org10.1083/jcb.201110132.

46. Srivastava R, Zhang J, Go GW, Narayanan A, Nottoli TP, Mani A. Impaired LRP6TCF7L2 Activity Enhances Smooth Muscle Cell Plasticity and Causes Coronary Artery Disease. Cell Rep. Oct 27 2015;13(4):746-759.

https://doi.org10.1016/j.celrep.2015.09.028.

47. Dieterich LC, Tacconi C, Menzi F, et al. Lymphatic MAFB regulates vascular patterning during developmental and pathological lymphangiogenesis. Angiogenesis. Apr 19 2020. https://doi.org10.1007/s10456-020-09721-1.

48. Jakus Z, Gleghorn JP, Enis DR, et al. Lymphatic function is required prenatally for lung inflation at birth. $J$ Exp Med. May 5 2014;211(5):815-26. https://doi.org10.1084/jem.20132308.

49. Bonet F, Pereira PNG, Bover O, Marques S, Inacio JM, Belo JA. CCBE1 is required for coronary vessel development and proper coronary artery stem formation in the mouse heart. Dev Dyn. Oct 2018;247(10):1135-1145.

https://doi.org10.1002/dvdy.24670.

50. Kotkow KJ, Orkin SH. Complexity of the erythroid transcription factor NF-E2 as revealed by gene targeting of the mouse p18 NF-E2 locus. Proc Natl Acad Sci U S A. Apr 16 1996;93(8):3514-8. https://doi.org10.1073/pnas.93.8.3514.

51. Iwata T, Kogame K, Toki T, Yokoyama M, Yamamoto M, Ito E. Structure and chromosome mapping of the human small maf-genes MAFG and MAFK. Cytogenet Cell Genet. 1998;82(1-2):88-90. https://doi.org10.1159/000015071.

52. Kazenwadel J, Harvey NL. Morphogenesis of the lymphatic vasculature: A focus on new progenitors and cellular mechanisms important for constructing lymphatic vessels. Dev Dyn. Mar 2016;245(3):209-19. https://doi.org10.1002/dvdy.24313.

53. Yu ZY, Sun D, Luo Y, Liu NF. Abnormal mural cell recruitment in lymphatic capillaries: a common pathological feature in chronic lymphedematous skin? Microcirculation. Oct 2016;23(7):495-502. https://doi.org10.1111/micc.12299.

54. Labun K, Montague TG, Gagnon JA, Thyme SB, Valen E. CHOPCHOP v2: a web tool for the next generation of CRISPR genome engineering. Nucleic Acids Res. Jul 8 2016;44(W1):W272-6. https://doi.org10.1093/nar/gkw398.

55. Lu H, Galeano MCR, Ott E, et al. Mutations in DZIP1L, which encodes a ciliarytransition-zone protein, cause autosomal recessive polycystic kidney disease. Nat Genet. Jul 2017;49(7):1025-1034. https://doi.org10.1038/ng.3871.

56. Hua R, Yu S, Liu M, Li H. A PCR-Based Method for RNA Probes and Applications in Neuroscience. Front Neurosci. 2018;12:266.

https://doi.org10.3389/fnins.2018.00266.

This article is protected by copyright. All rights reserved. 


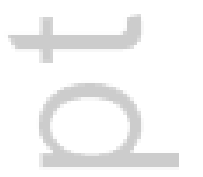




\section{FIGURE LEGENDS}

\section{Figure 1. Generation of a Mafb mutant mouse strain.}

(A) CRISPR/Cas9 genetic engineering design. Single-guide RNA sets were designed to delete the basic leucine zipper DNA binding domain (bZIP) of the coding region of the Mafb gene. (B and C) PCR, RT-PCR and subsequent sequencing of both products revealed a 56bp deletion in the Mafb bZIP domain, leading to an early stop codon (red rectangle) by frame shift.

(D) Overall appearance of Mafb $b^{456 / 456}$ and control littermate embryos at E16.5. Representative images are shown from 157 control and 55 Mafb ${ }^{456 / \Delta 56}$ embryos examined from 30 litters. Scale bar $2 \mathrm{~mm}$.

(E) Mafb mutation segregation at different embryonic stages and into early postnatal stages. Mafb deficient mice do not survive longer after birth.

(F) Cyanotic state of $M a f b^{456 / 456}$ after natural birth, insert shows zoom-in of fingertips exhibiting peripheral cyanosis (red arrows). Representative littermates are shown from 24 control and $10 \mathrm{Mafb}{ }^{456 / 456}$ pups examined from 6 litters. Images were obtained within 30 minutes from birth. Scale bar $5 \mathrm{~mm}$.

(G) Heart size and structure of control littermates and Mafb $b^{456 / 456}$ embryos at P0 by H\&E staining. Images are representative of 4 control and $4 M a f b^{456 / \Delta 56}$ embryos examined from 3 litters. Scale bar 500uM. 


\section{Figure 2. Histological and immunofluorescence analysis of Mafb mutant lungs.}

(A) H\&E staining of lung sections showing overall alveolar structure in the cyanotic $M a f b^{456 / 456}$ and control littermate neonates. Periodic acid-Schiff (PAS) staining to show the levels of the surfactant precursor glycogen in the lungs of $M a f^{456 / \Delta 56}$ and control littermate neonates. Red arrows indicate accumulation of glycogen. Masson's trichrome (TRI) staining to assess levels of fibrosis (collagen shown in blue) in the lungs of $M a b^{456 / \Delta 56}$ and control littermate neonates. Scale Bar 100uM for H\&E and PAS staining. Scale Bar 50uM for Masson’s trichrome staining.

(B) Measurement of alveolar septal thickness $(\mu \mathrm{M}) \mathrm{Mafb} \mathrm{b}^{456 / \Delta 56}$ and littermate controls neonates, $\mathrm{n}=7$ controls and 7 Mafb mutants from 4 litters.

(C) Total DNA content in lungs from $M a f b^{456 / 456}$ and littermate controls neonates. $n=4$ controls and 4 MafB mutants from 2 litters.

(D) Mafb sectional in situ hybridisation (SISH) in lung sections. Red arrows indicate Mafb expression in the bronchioles, asterisk indicates the vein. Blue box insert and arrow indicates expression detected in the lymphatic vessels. Scale Bar 100uM.

(E) Lung sections from Mafb $b^{456 / 456}$ and control littermates were stained for markers of lymphatic endothelial cells (LYVE-1 and PROX1), Type I cells (PODOPLANIN [PDPN] and CAVEOLIN1 [CAV1]), alpha-smooth muscle actin (SMA) and pericytes (NG2). Images are representative of 3 control and $3 \mathrm{Mafb} \mathrm{f56/456}^{4 m b r y o s}$ examined from 2 litters. Scale bar 20uM. 
Figure 3. MAFB deficient embryonic dermal lymphatics display mild and transient defects in development.

(A and B) Representative confocal images of E14.5 and E16.5 embryonic back skin stained for lymphatic vessels with NEUROPILIN-2 (NRP2) and blood vessels with ENDOMUCIN (EMCN). E14.5 and E16.5 images are representative of 7 control and 7 Mafb ${ }^{\Delta 56 / \Delta 56}$ embryos examined from 6 and 5 litters respectively. Scale bar 400uM.

(C) Quantification of E14.5dpc embryonic back skin, within an area of $2000 \mathrm{uM}^{2}$ from midline towards the sides, of vessel junctions or branch points and total number of loops. Lymphatic vessel (LV) width of the migrating vessels closer to the midline, number of PROX1 (PROX1) and NEUROPILIN-2 (NRP2) positive cells and distance from the midline to these migrating vessels. Vessel width of the blood vessels (BV) between branch points.

(D) Quantifications on E16.5dpc embryonic back skin, within an area of $2000 \mathrm{uM}^{2}$ from midline towards the sides, of vessel junctions or branch points and total number of loops. Lymphatic vessel (LV) width of the migrating vessels closer to the midline, number of PROX1 (PROX1) and NEUROPILIN-2 (NRP2) positive cells and distance from the midline to these migrating vessels. Total of area covered with blood vessels (ENDOMUCIN [EMCN]) within an area of $1340 \mathrm{uM}^{2}$.

This article is protected by copyright. All rights reserved. 
Figure 4. Prenatal and postnatal diaphragm lymphatics display defects in morphogenesis in Mafb mutant mice.

(A and B) Lymphatic vessels on the pleural side of the diaphragmatic muscle.

(A) Wide-field images of diaphragm whole mounts stained for NEUROPILIN-2 (NRP2) at E16.5. Dotted lines mark the quantified area. Images are representative of 5 control and 6 $M a f b^{456 / 456}$ embryos examined from 4 litters. Scale bar 300uM. Stars mark the central tendon region. (B) Wide-field images of diaphragms whole mounts stained for NEUROPILIN-2 (NRP2) at P0. Images are representative of 6 control and 6 Mafb $b^{456 / 456}$ embryos examined from 4 litters. Scale bar 300uM. Stars mark the central tendon region.

(C) Quantification of diaphragmatic lymphatic network at E16.5. Percentage of area in the diaphragm covered by lymphatic vessels (LV). Number of PROX1 (PROX1) and NEUROPILIN-2 (NRP2) positive cells in migrating vessels (MV). Lymphatic vessel width in a 50um segment of the middle of a vessel. Number of PROX1 and NEUROPILIN-2 positive cells at a branch point (BP).

(D) Quantification of diaphragmatic blood vascular network at E16.5, 3 control and 3 $M a f b^{456 / 456}$ embryos examined from 2 litters. Blood vessel (BV) width within branch points and number of branch point in the blood vasculature.

(E) Quantification of diaphragmatic lymphatic network at P0. Percentage of area in the diaphragm covered by Lymphatic vessels (LV). Number of PROX1 (PROX1) and NEUROPILIN-2 (NRP-2) positive cells in migrating vessels (MV). Lymphatic vessel width in a 50um segment of the middle of a vessel. Number of PROX1 (PROX1) and NEUROPILIN-2 (NRP-2) positive cells at a branch point (BP).

(F) Quantification of diaphragmatic blood vascular network at P0, 3 control and 3 Mafb ${ }^{456 / 456}$ pups examined from 2 litters. Blood vessel (BV) width within branch points and number of branch point in the blood vasculature. Data are presented as means \pm SEM.

This article is protected by copyright. All rights reserved. 
Figure 5. Diaphragm lymphatics display phenotypes during their maturation in MafB mutant mice.

(A) Representative high-magnification confocal images of E16.5 embryonic diaphragm stained for PROX1 (PROX1), NEUROPILIN-2 (NRP2) and ENDOMUCIN (EMCN). Diaphragm images are representative of 5 control and $6 \mathrm{Mafb} b^{456 / 456}$ embryos examined from 4 litters.

(B and C) Quantification in 50uM tip of migrating vessels of (B) lymphatic vessel (LV) width at the tip of migrating vessel, (C) Distance between PROX1 (PROX1) and NEUROPILIN-2 (NRP2) positive cells nuclei at the tip of migrating vessel. Scale bar 100uM. Data are presented as means \pm SEM.

(D) Representative high-magnification confocal images of E18.5 embryonic mesenteric collecting lymphatic vessels stained for NEUROPILIN-2 (NRP2) and PROX1 (PROX1). Red arrows indicate PROX1 high regions. Mesenteric images are representative of 2-3 vessels from 3 control and 3 mutant embryos examined from 2 litters. (E) Quantification of length of collecting lymphatic vessel in the mesentery, number of PROX1 high regions in the collecting lymphatic vessels and ratio between number of PROX1 high regions and length of collecting lymphatic vessels. Scale bar 100uM. Data are presented as means \pm SEM.

This article is protected by copyright. All rights reserved. 
Figure 6. Mural cell coverage is increased in MAFB deficient lymphatics.

(A) Low and high-magnification confocal images of E16.5 embryonic back skin stained for alpha-smooth muscle actin (SMA) and NEUROPILIN-2 (NRP2). Images are representative of 3 control and $3 \mathrm{Mafb}^{456 / 456}$ embryos examined from 2 litters. Scale bar 100uM.

(B) High- magnification confocal images of diaphragms at P0 stained for SMA, NRP-2 and ENDOMUCIN (EMCN). Images are representative of 3 control and 3 Mafb $b^{456 / \Delta 56}$ pups examined from 2 litters. Scale bar 100uM.

(C) Example of image rendering (Imaris) used for SMA coverage analysis in embryonic back skin and neonatal diaphragm. Scale bar 150uM.

(D and E) Percentage of surface area of lymphatic vessels covered by alpha-smooth muscle actin (SMA) in dermal skin at E16.5 (D) and diaphragms at P0 (E). Data are presented as means \pm SEM. 
A Mafb

\begin{tabular}{l|l|l|}
\hline ATG & (bZIP & STOP \\
\hline \multicolumn{3}{c}{ EXON 1}
\end{tabular}

$\mathrm{Mafb}^{\Delta 56 / \Delta 56}$

\begin{tabular}{|l|l|l|}
\hline ATG & & STOP \\
\hline
\end{tabular}

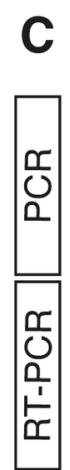

D

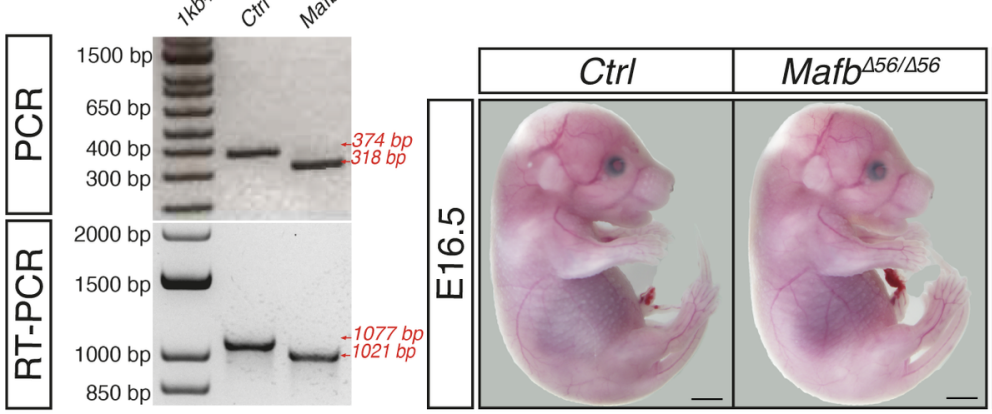

E

\begin{tabular}{|lrrrr|}
\hline Stage & \multicolumn{1}{c}{ n } & Mafb $^{+/+}$ & Mafb $^{+/ \Delta^{56}}$ & Mafb $\triangle^{56 / 456}$ \\
E10.5 & 56 & $26.8 \%$ & $39.3 \%$ & $33.9 \%$ \\
E11.5 & 41 & $26.8 \%$ & $46.3 \%$ & $26.8 \%$ \\
E14.5 & 170 & $17.6 \%$ & $55.3 \%$ & $27.1 \%$ \\
E16.5 & 212 & $30.7 \%$ & $43.4 \%$ & $25.9 \%$ \\
E18.5 & 104 & $27.9 \%$ & $53.9 \%$ & $18.3 \%$ \\
PO & 34 & $26.5 \%$ & $44.1 \%$ & $29.4 \%$ \\
P0.5 & 32 & $37.5 \%$ & $62.5 \%$ & $0.0 \%$ \\
\hline
\end{tabular}

B

3.

\section{BASIC-LEUCINE ZIPPER DOMAIN (bZIP)}

AAACGCGGGGCTTCACCAAGGACGC

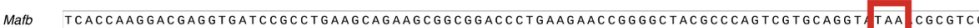
TAA CGCGTC

STOP 

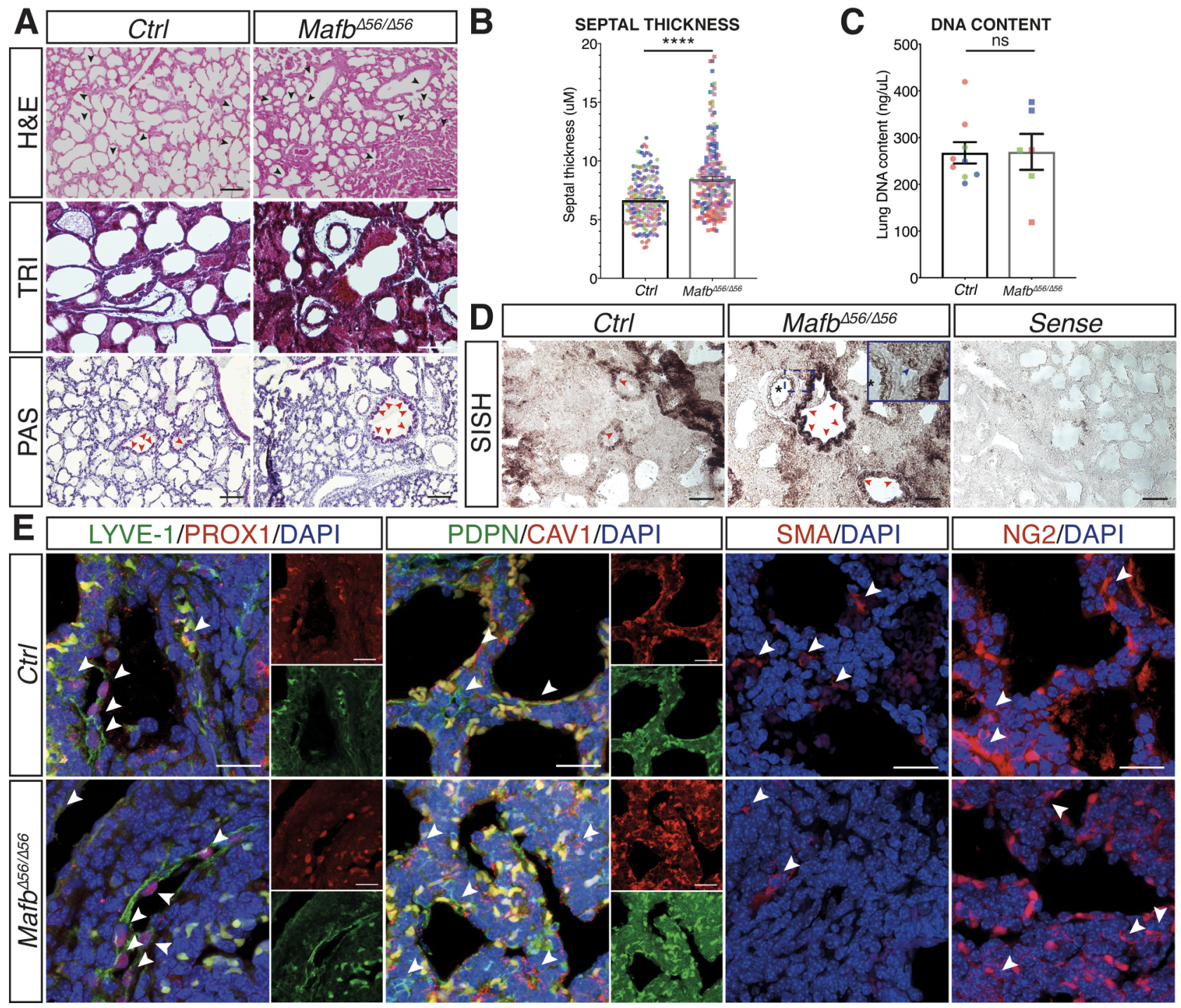

DVDY_209_Figure_2.tif 


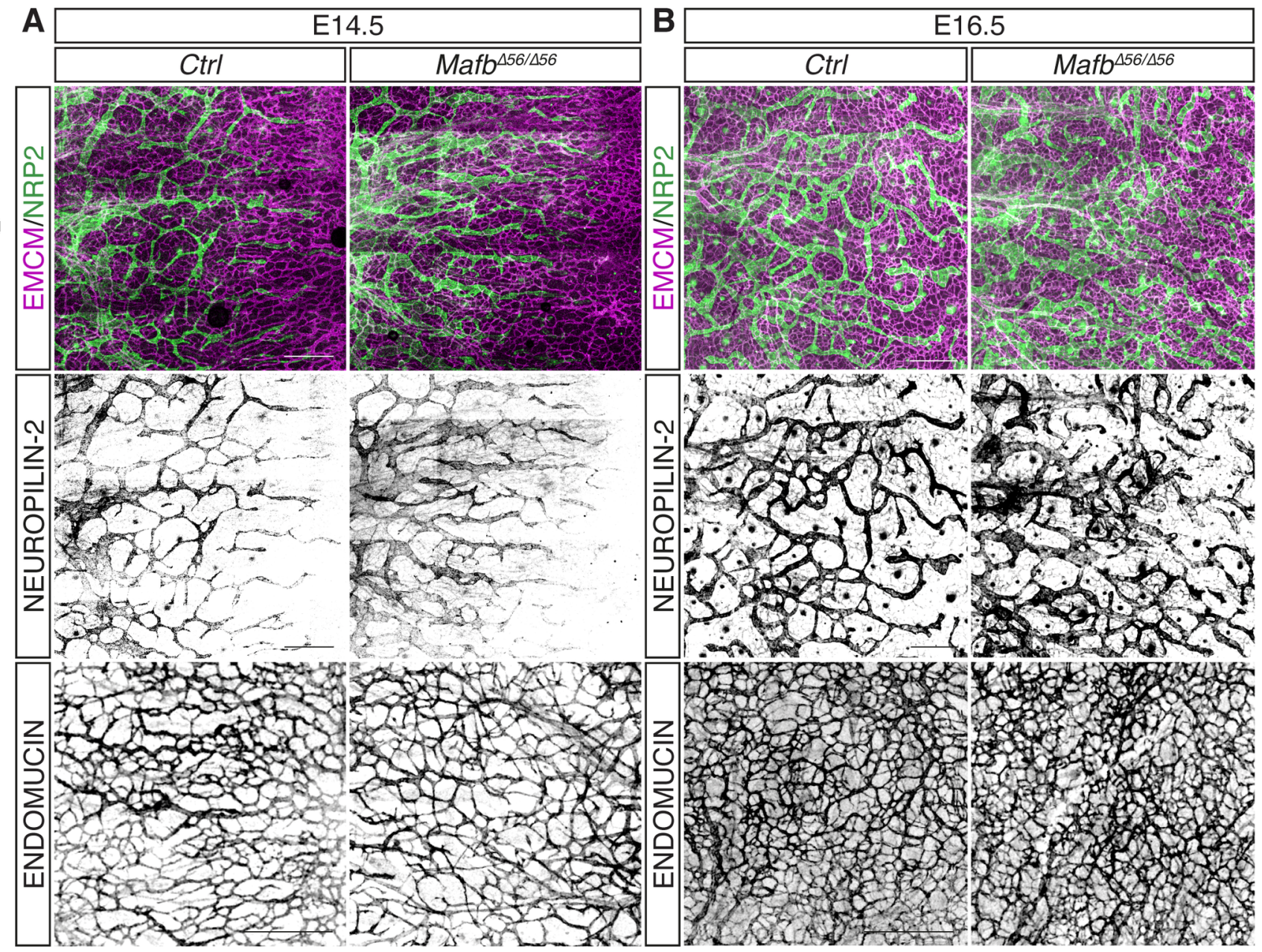

C NUMBER OF NUMBER OF LYMPHATIC VESSEL

C BRANCH POINTS

LYMPHATIC V
WIDTH

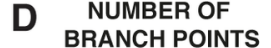

NUMBER OF

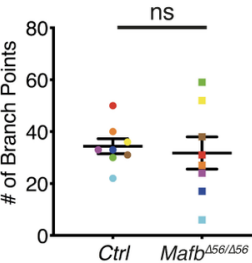

PROX1 POSITIVE

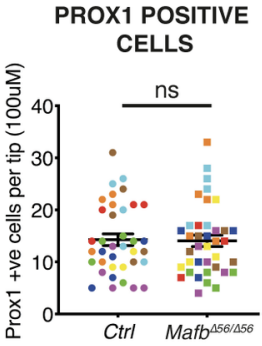

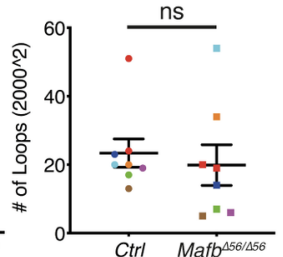

DISTANCE FROM MIDLINE

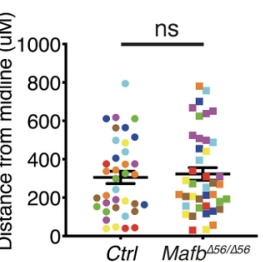

LYMPHATIC VESSEL

WIDTH

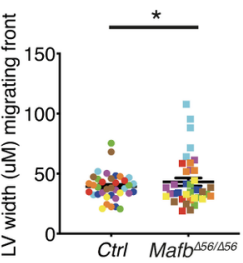

$\%$ OF BLOOD VESSEL AREA

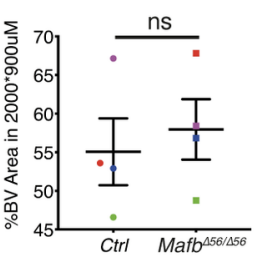

DVDY_209_Figure_3.tif 

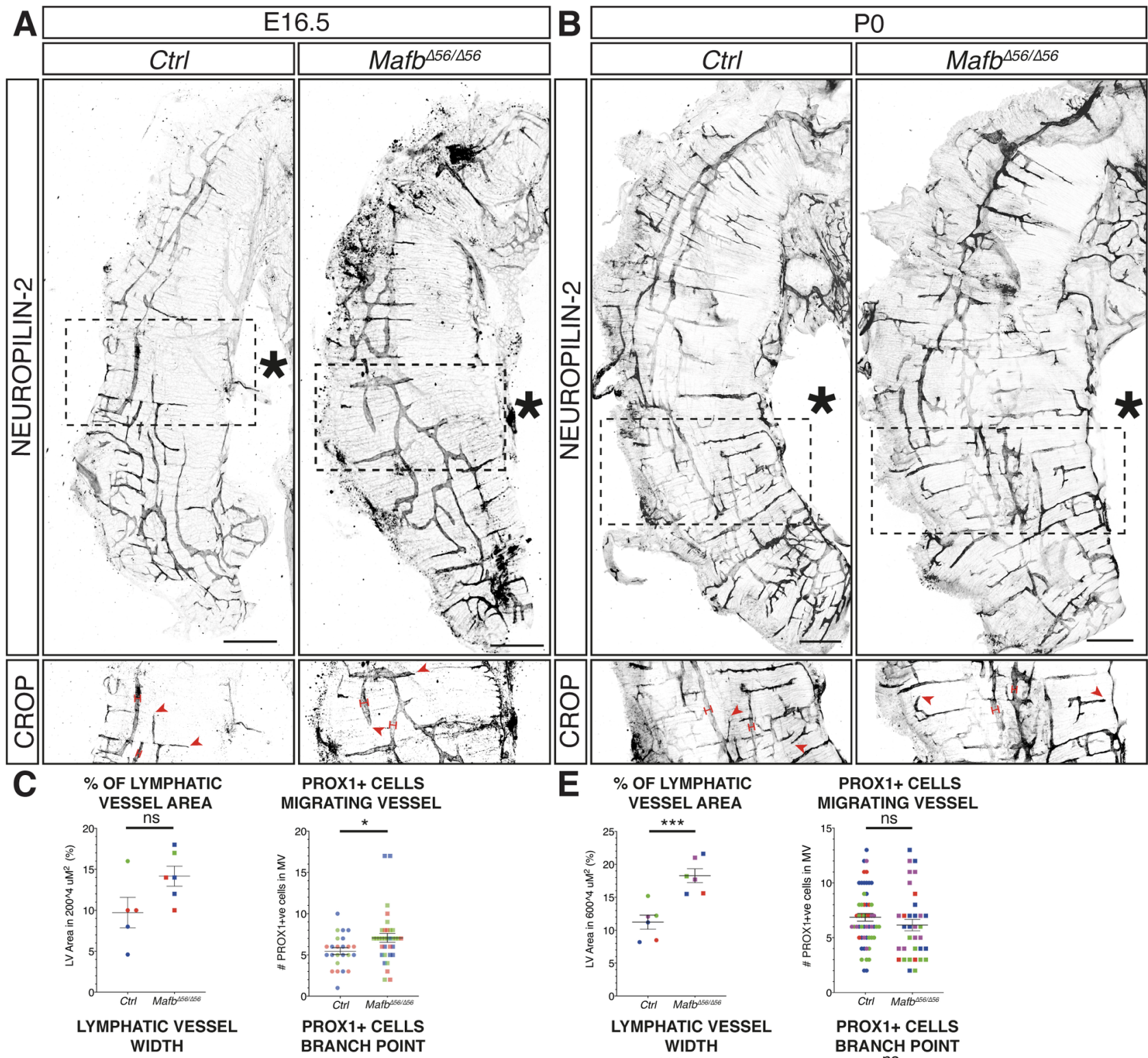

E \% OF LYMPHATIC
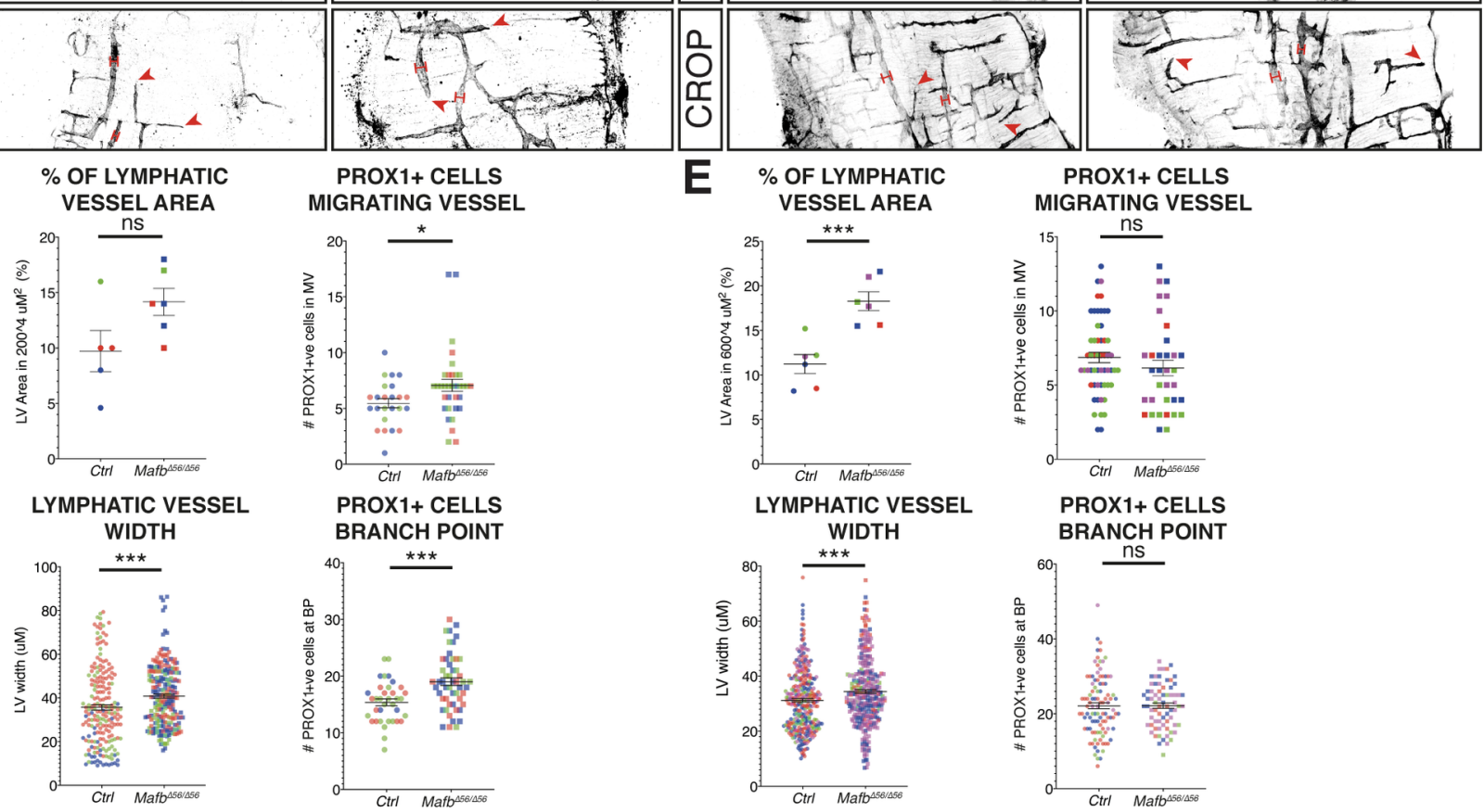

D BLOOD VESSEL
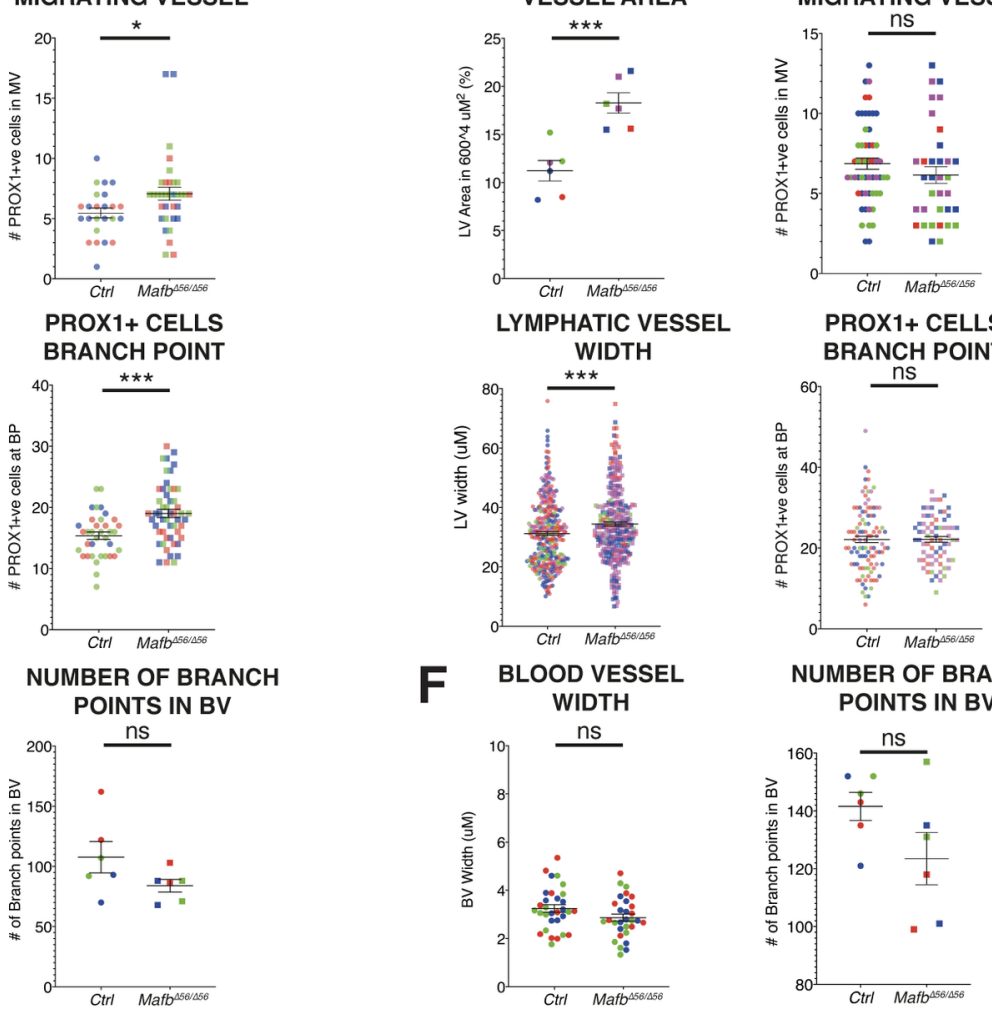

LYMPHATIC VESSEL
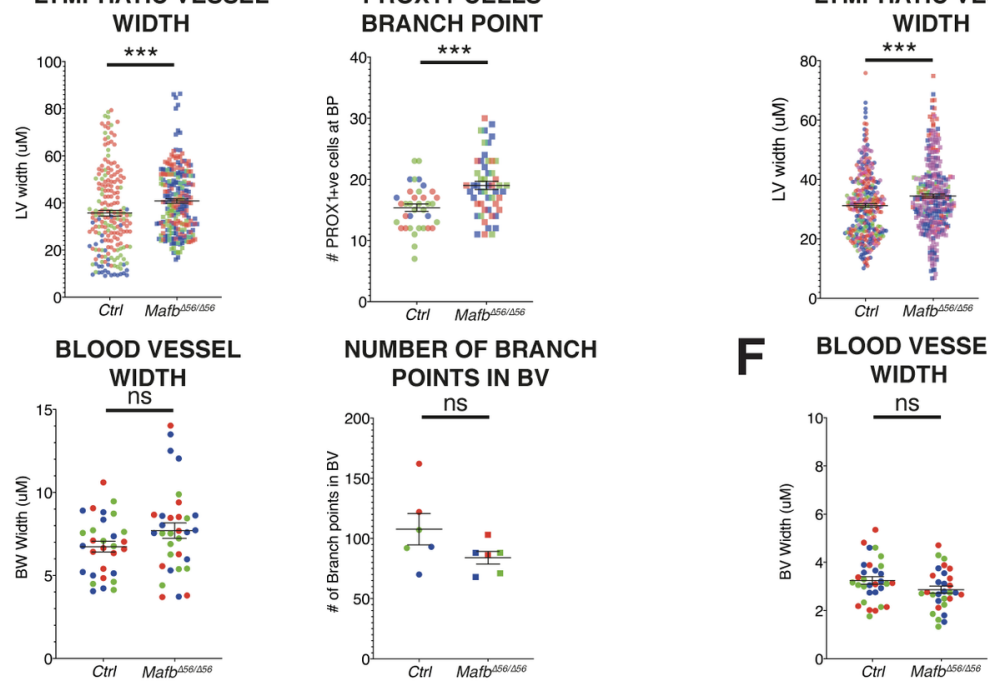

F BLOOD VESSEL

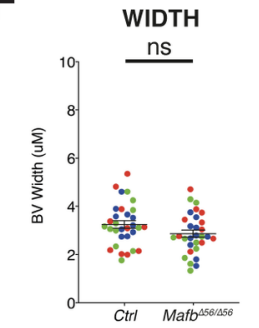

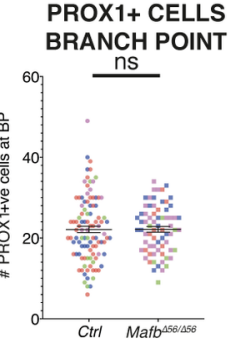

NUMBER OF BRANCH POINTS IN BV

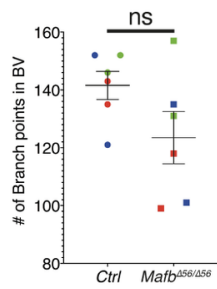

DVDY_209_Figure_4.tif 


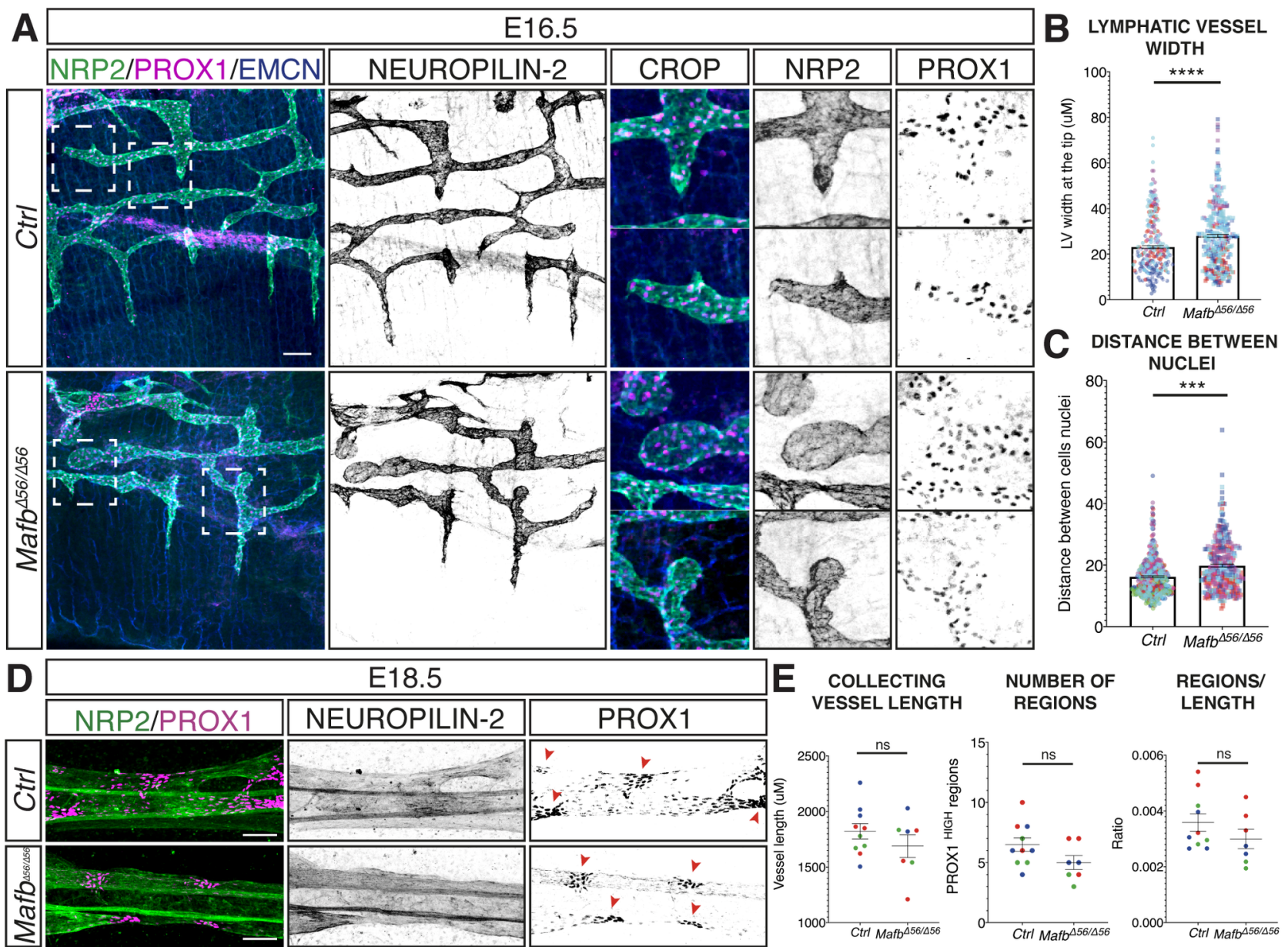

DVDY_209_Figure_5.tif 

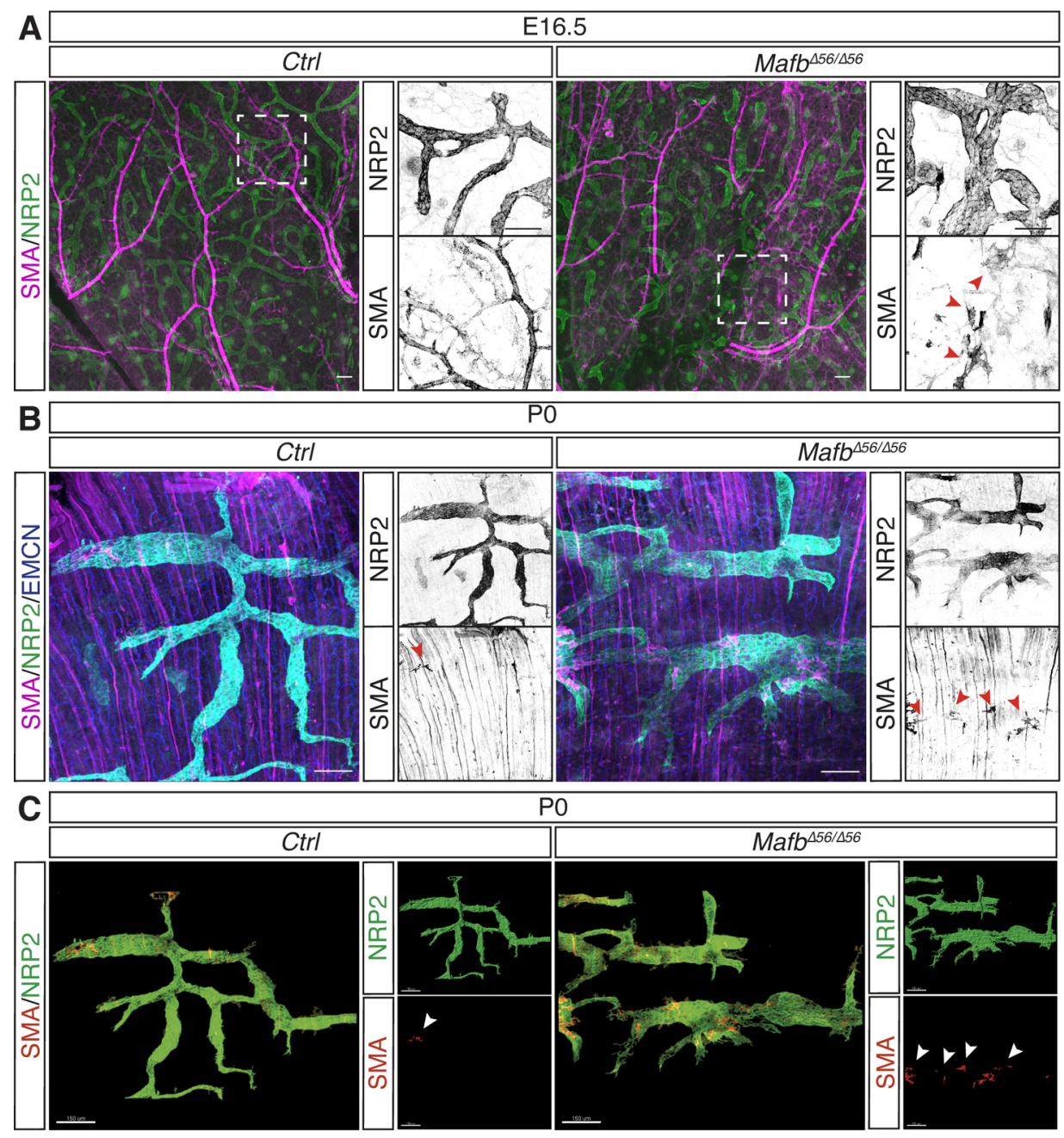

PERCENTAGE OF aSMA COVERAGE ON
DERMAL LYMPHATIC VESSELS

E PERCENTAGE OF aSMA COVERAGE ON

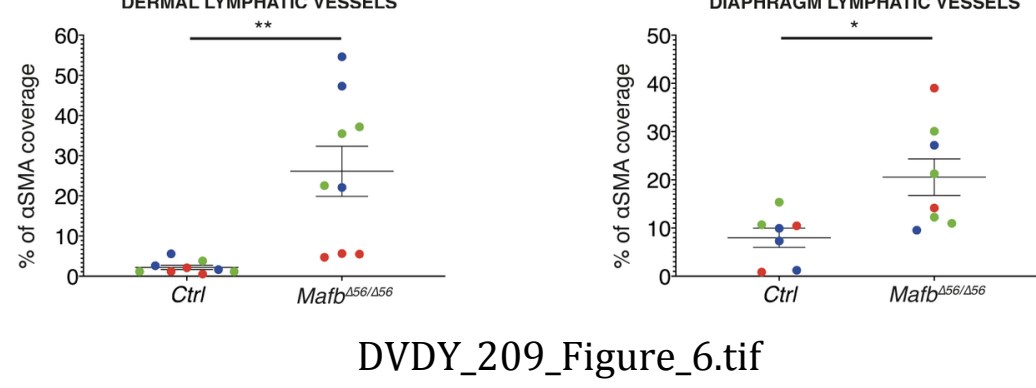

This article is protected by copyright. All rights reserved. 